Elmir Germani, engenheiro (ITA), trabalhou na área de planejamento de tráfego da Cia. do

Metropolitano de São Paulo, participou do grupo que assessorou o ministro dos Transportes na ciração da Empresa Brasileira dos

Transportes Urbanos - EBTU. Ex-

superintendente da área de transporte da Empresa Metropolitana de Planejamento da Grande São Paulo EMPLASA -, atualmente é diretor da Cia. de Engenharia da Tráfego - CET.

\title{
Para onde vai o nosso transporte coletivo?
}

\section{O problema dos deslocamentos urbanos}

Mesmo antes do início da crise do petróleo, em 1973, os transportes coletivos eram considerados, nos meios técnicos principalmente, melhor solução do que o transporte privado, para o problema dos deslocamentos urbanos de pessoas.

Com efeito, além de energeticamente mais eficiente, os transportes coletivos consomem muito menos espaço que os automóveis. E o espaço nas cidades, sobretudo nas áreas centrais das grandes cidades, é um bem extremamente escasso e valioso. Como seu uso é, em geral, livre de qualquer taxação específica, a grande demanda acaba provocando congestionamentos que, por sua vez, acarretam enormes custos sociais e desperdício de combustivel.

Estes fatos já eram reconhecidos nas conclusões do 1 ? $^{\circ}$ Congresso de Trânsito da Cídade de São Paulo, realizado em junho de 1949. Recomendavase "que, no trânsito de veículos em geral, a circulação de veículos de transporte coletivo tenha preferência sobre os demais". A Comissão de Estacionamento daquele congresso fazia a mesma recomendação "tendo em vista a maior soma de serviços que [os veículos de transporte coletivo] prestam à comunidade".

Desde aquela época, as vantagens reconhecidas do transporte coletivo sobre o particular somente tiveram motivos de acentuar-se:

Em primeiro lugar, pela concentração da po- pulação em zonas urbanas, propiciando uma disputa acirrada pelo espaço, tanto por aqueles destinados a abrigar atividades como pelos destinados à circulação.

Até meados dos anos 1960 éramos um país rural - menos da metade da população habitava zonas urbanas. Cerca de 15 anos depois o censo de 1980 já indicava a população urbana correspondendo a mais de $2 / 3$ da total. Na última década, enquanto a população rural experimentou um decréscimo $(-68 \%)$, a urbana aumentou em $55 \%$. Quase $1 / 3$ de toda a população concentra-se em apenas 9 aglomerados urbanos: as regiões metropolitanas (tabela 1).

Tabela 1 - População brasileira urbana e rural

(em milhares de hab.)

\begin{tabular}{l|ll|ll}
\hline População urbana & \multicolumn{2}{|c|}{1979} & \multicolumn{2}{c}{1980} \\
\hline - Regiões metropolitanas & 22.344 & $24 \%$ & 32.940 & $28 \%$ \\
- Demais cidades & 29.741 & $32 \%$ & 47.539 & $40 \%$ \\
Subtotal & 52.085 & $56 \%$ & 80.479 & $68 \%$ \\
População rural & 41.054 & $44 \%$ & 38.620 & $32 \%$ \\
\hline Total & 93.139 & $100 \%$ & 119.099 & $100 \%$ \\
\hline
\end{tabular}

Fonte: IBGE

Essa concentração torna ainda mais grave o problema, pois os conflitos da circulação urbana tendem a crescer mais que proporcionalmente ao tamanho da cidade.

Em segundo lugar, pelo violento crescimento verificado na frota de veículos, mais especificamente de automóveis (que correspondem a $75 \%$ da frota 
total). Aparentemente a propriedade de veículos não tem sido seriamente afetada nos últimos anos pela crise de combustíveis. No período de 1974/1981 o número de carros por habitantes aumentou em $150 \%$.

Tabela 2 - Evolução da frota nacional de veículos Período 1974 / 1981

\begin{tabular}{c|c|c|c}
\hline Ano & $\begin{array}{c}\text { População } \\
\text { milhões/hab. }\end{array}$ & $\begin{array}{c}\text { Frota } \\
\text { mil veículos }\end{array}$ & hab./veículo \\
\hline 1974 & 102,8 & 4.243 & 24,2 \\
1975 & 105,3 & 5.487 & 19,2 \\
1976 & 107,9 & 6.641 & 16,2 \\
1977 & 110,6 & 7.657 & 14,4 \\
1978 & 113,4 & 8.961 & 12,7 \\
1979 & 116,2 & 9.710 & 12,0 \\
1980 & 119,1 & 10.767 & 11,0 \\
1981 & 122,1 & 11.604 & 10,5 \\
\hline
\end{tabular}

Fonte: Serpro-Cad.TRU, Suma Econômica set./82

Um período de economia instável, na medida que diminua a disponibilidade para investimentos tanto na aquisição como na manutenção de veículos, poderá reduzir esse ritmo. Tão logo se estabilize a economia, o que se pode esperar sem dúvida é uma retomada dos índices de crescimento. A relação constatada entre o PIB per capita e a propriedade de carros está indicada na figura 1.

Em terceiro lugar, o transporte coletivo se tor- na ainda mais vantajoso sobre o particular mais recentemente, pela crise do petróleo. Neste caso, a ineficiência energética do automóvel se amplia pelos congestionamentos provocados por sua ineficácia no uso do espaço.

O problema com que nos defrontamos é que, apesar de todas essas evidências - e em alguns casos por causa delas - está comprovado que, ao longo do tempo, os transportes coletivos têm sido relegados ao quase abandono e conseqüentemente perderam terreno para o automóvel.

\section{Que evolução se pode esperar na demanda?}

Se nenhum esforço adicional for realizado, o que se pode esperar é um declínio em futuro próximo na utilização dos transportes coletivos. O exemplo mais típico é o dos Estados Unidos que, tendo atingido em 1945 cerca de 19 bilhões de viagens por transporte coletivo, viram esse valor ser reduzido, apesar do aumento populacional, para menos de $1 / 3$ (cerca de 6 bilhões de viagens) na década de 1970. Somente nos últimos anos está se notando uma ligeira tendência ao crescimento ${ }^{1}$, fruto de um gigantesco esforço do governo federal desde o início dos anos 70 com a criação da UMTA (Urban Mass Transportation Administration), que passou a financiar e subsidiar os investimentos nessa área. As sub-

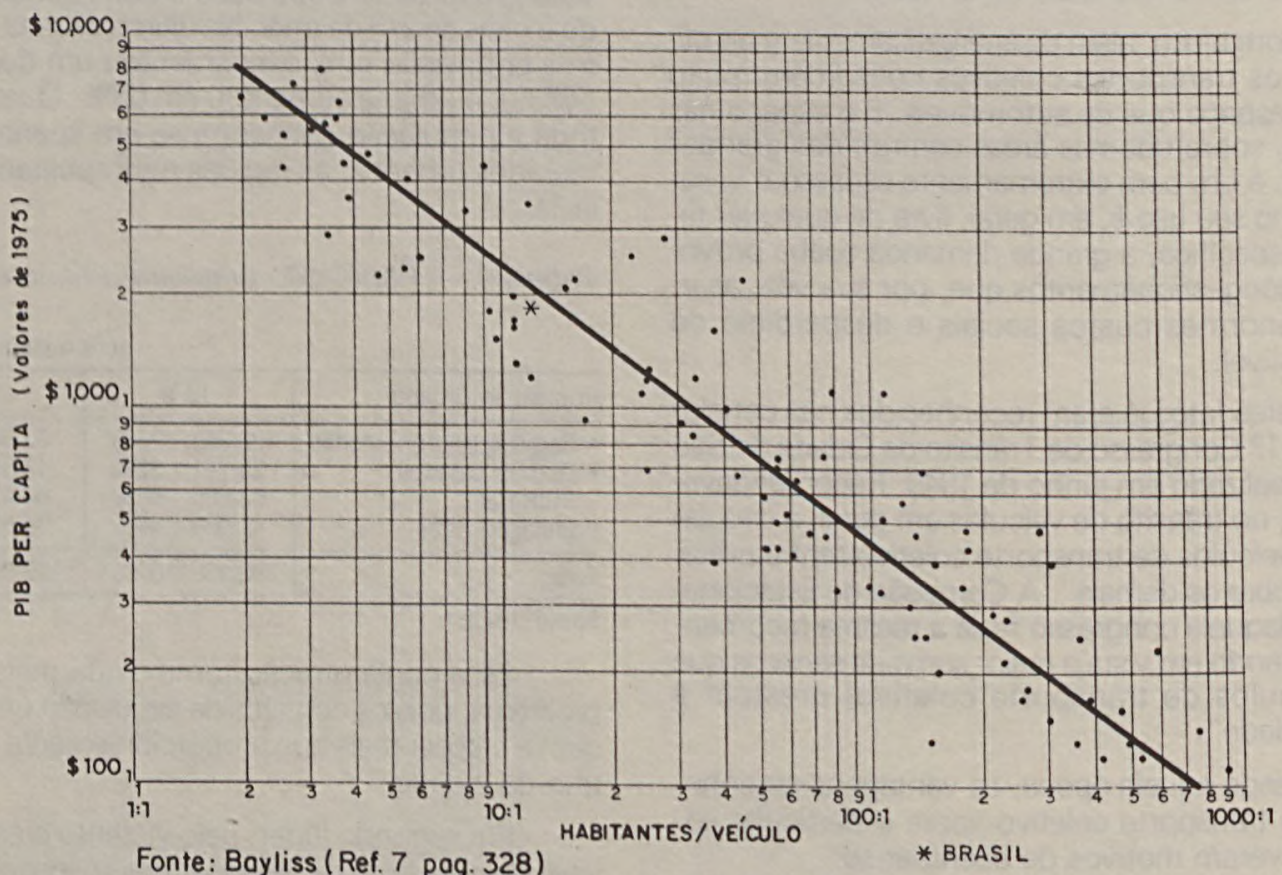

FIG. 1 - TAXAS NACIONAIS DE PROPRIEDADE DE CARROS $\times$ PIB PER CAPITA 
venções federais passaram de 12 milhões de dóla res em 1968 para 2.037 milhões de dólares dez anos mais tarde. 2 A partir de 1974 a UMTA passou a subsidiar também os déficits operacionais.

Um círculo vicioso se estabeleceu, representado pela redução da demanda, conseqüente redução das receitas, provocando aumento das tarifas que, por sua vez, acarretam em nova redução da demanda.

A conseqüência da intervenção maciça do governo no setor, a fim de quebrar esse círculo vicioso, acabou resultando no quase total alijamento do setor privado da área de transportes coletivos urbanos.

A solução característica adotada, principalmente nas cidades maiores, foi a da criação de empresas públicas regionais de transportes coletivos, que absorveram os serviços existentes.

Da mesma forma na Grã-Bretanha observou-se, na última década, um decrescimento contínuo das viagens de transporte público por ônibus de um total de 9,8 bilhões de viagens, em 1969, para 7,1 bilhões em $1973 .{ }^{3}$ Em termos percentuais, os ônibus perderam fatia significativa do total de viagem: passaram de $35,1 \%$, em 1965 , para $18,7 \%$ praticamente a metade - em 1975/76. Em Londres, por exemplo, o número de viagens anuais de trans- porte público per capita vem decrescendo desde 1950, quando atingiu 450 viagens/hab./ano, caindo para cerca de 260 viagens/hab./ano em 19704 - valor este que, aparentemente, vem se mantendo constante.

Também na Alemanha Federal houve um decréscimo na utilização dos transporte coletivos, percebendo-se uma estabilização, com ligeira tendência a aumento a partir de 1978 (Vide Isaac, J.K. \& Brockhoff, E. op. cit.).

$\mathrm{Na}$ França, igualmente, até o início da crise energética essa utilização vinha decrescendo sistematicamente. ${ }^{5}$ Mesmo em paises menos desenvolvidos, como por exemplo a Hungria, reportam-se declínios na utilização dos transportes coletivos, em virtude do aumento da propriedade de carros. ${ }^{6} \mathrm{O}$ fato é que o desenvolvimento traz o automóvel e este substitui, via de regra, o transporte coletivo.

Uma interessante análise nesse sentido foi realizada por Bayliss. ${ }^{7}$ Em seu trabalho, o autor estima que a quantidade de viagens por transporte público cresce com o desenvolvimento econômico até que se atinja a faixa dos US\$1.000 per capita de PNB. A partir desse ponto de utilização do automóvel e motocicleta passa a crescer rapidamente, enquanto a dos transportes públicos declinam (figura 2).

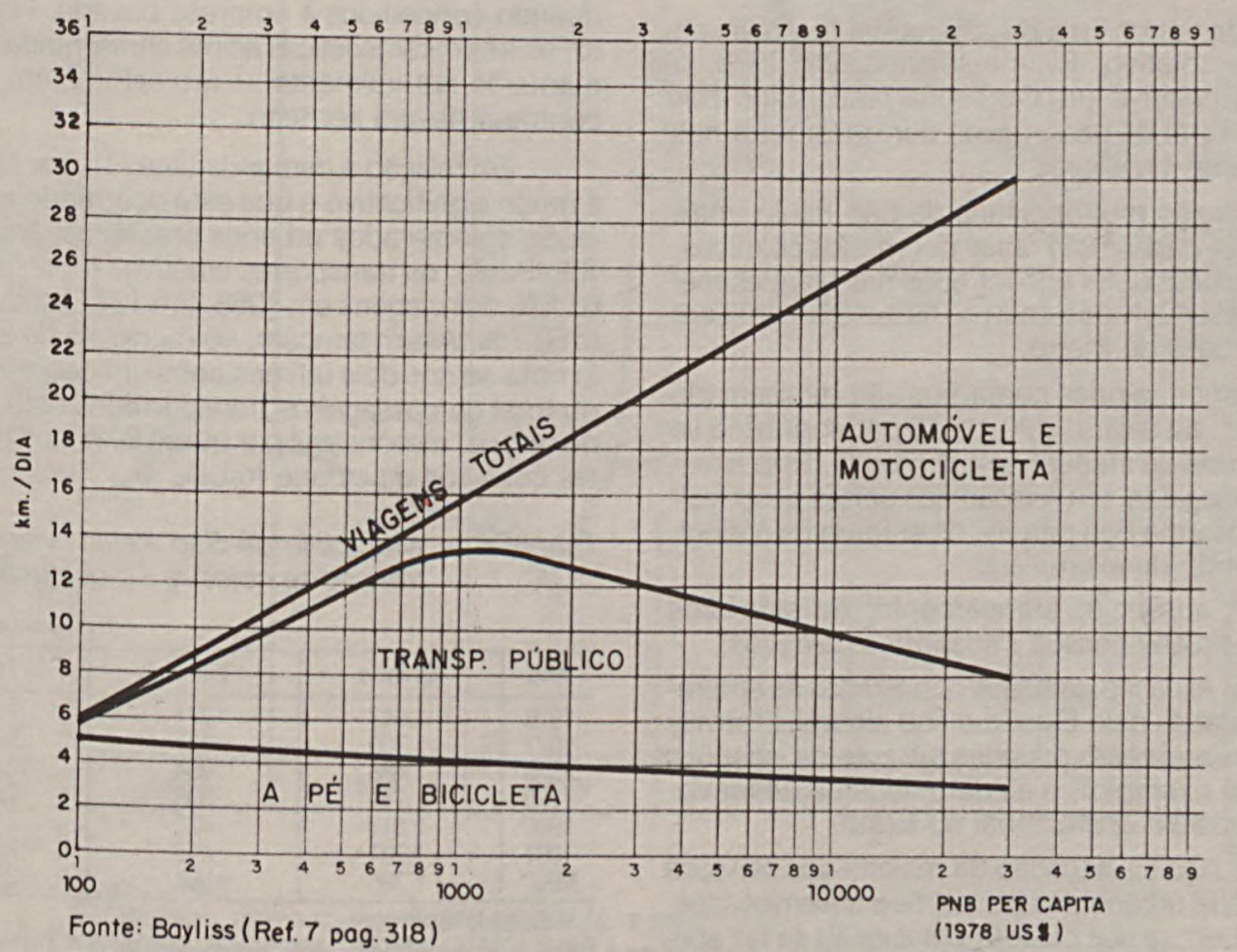

FIG.2 - VARIACÃO DAS VIAGENS URBANAS COM A RENDA 
Mostra-se na figura 2 a distância percorrida, . ao invés do número de viagens, pois as viagens a pé e de bicicleta são, em média, muito menores em ex. tensão que aquelas dos modos motorizados.

O que se pode esperar, portanto, já que estamos com a PNB da ordem de US\$2.500,00 (valores de 1981), é que essas tendências comecem a manifestar-se também em nosso país. E se ainda não se manifestaram de forma mais contundente, devese provavelmente à extrema distribuição da renda desigual que deixa um enorme contingente de brasileiros sem opção de possuir ou manter um carro particular.

\section{Em que fase €stamos atualmente?}

Em certo sentido, a situação de nossos transportes coletivos encontra-se ainda num ponto onde muitos estão lutando para chegar. Obviamente não nos referimos à qualidade dos serviços, mas a aspectos decorrentes inclusive de nossa condição de subdesenvolvimento. Deveríamos, no entanto, capitalizar essa situação, não deixando escapar condições que seriam convenientes, ou, pelo menos, que deveriam ser mantidas.

Examinemos três aspectos de nossa situação:

1. As características de nossa demanda

Ainda temos uma divisão modal favorável ao transporte coletivo. Estima-se ${ }^{8}$ que, em 1975, o transporte coletivo urbano tenha respondido por $67,6 \%$ do total de passageiros por quilômetro nas áreas urbanas brasileiras.

Na região metropolitana de São Paulo, mais de $60 \%$ das viagens são feitas por modos coletivos, valor superior àqueles encontrados nas grandes metrópoles desenvolvidas, mesmo as que contam com extensas redes de metrô.

Estamos, ainda, numa posição de mercado comprador, ou seja, o esforço do poder público se faz no sentido de atender-se à demanda. Essa situação é 'privilegiada' em relação aos países desenvolvidos, onde uma boa parcela do esforço está dirigida no sentido de estimulá-la.

2. A ausência, praticamente, de subsídios operacionais aos nossos transportes coletivos

Com exceção daqueles concedidos às empresas controladas pelo Estado e sob algumas formas também às empresas privadas (através de isenções fiscais, por exemplo), é ainda praticamente inexistente o subsídio operacional no Brasil.

Esta não é a situação da maioria dos serviços de transporte urbano dos países mais desenvolvidos, onde a cobertura dos custos operacionais se faz apenas parcialmente pelas receitas tarifárias, o restan- te provindo dos subsídios das mais diversas formas e fontes.

A tabela 3 mostra a taxa de cobertura dos custos de transporte pela receita tarifária em uma seleção de cidades de mais de 2 milhões de habitantes.

Tabela 3 - Taxa de cobertura dos custos pela tarifa

\begin{tabular}{l|c|c}
\hline $\begin{array}{c}\text {,Aglomeração } \\
\text { urbana }\end{array}$ & $\begin{array}{c}\text { Populacão } \\
\text { (milhões hab.) }\end{array}$ & $\begin{array}{c}\text { Taxa de cobertura dos custos } \\
\text { operacionais p/tarifa }\end{array}$ \\
\hline Los Angeles & 10,0 & $42 \%$ \\
Paris & 9,4 & $38 \%$ \\
Londres & 6,9 & $71 \%$ \\
Frankfurt & 2,4 & $38 \%$ \\
Hamburgo & 2,4 & $80 \%$ \\
Madrid & 3,4 & $69 \%$ \\
Milão & 1,7 & $34 \%$ \\
Roma & 2,9 & $20 \%$ \\
Toronto & 2,1 & $68 \%$ \\
\hline
\end{tabular}

Fonte: UITP - Congresso 1981/5

3. A operação, por empresas privadas, da maioria de nossos serviços de transportes coletivos por ônibus

É notória a maior capacidade da iniciativa privada em produzir serviços mais eficientemente que as empresas controladas pelo Estado. Não obstante, a tendência mundial tem sido de estatização dos serviços, um dos motivos principais sendo a dificuldade de controle dos subsídios operacionais diretos, quando concedidos à empresa privada. No entanto, as três características acima apresentadas não se manterão naturalmente - um esforço em sentido contrário deverá ser feito.

Em relação à demanda (item 1), por exemplo, é muito significativo o que está ocorrendo nos principais aglomerados urbanos brasileiros. Na grande São Paulo, os transportes coletivos representavam $63,5 \%$ das viagens em 1968. Em 1977 baixaram para $60,7 \%$. Assim também, no município de São Paulo nota-se nos dois últimos anos um decrescimento no total de passageiros transportados pelo sistema de ônibus, responsável por quase $80 \%$ dos transportes coletivos da cidade (tabela 4).

Tabela 4 - Município de São Paulo: viagens por transporte coletivo - evolução

\begin{tabular}{c|c|c|c}
\multicolumn{3}{|c}{ (milhões de viagens) } \\
\hline Ano & Onibus & Trilhos & Total \\
\hline 1976 & 1.647 & 277 & 1.954 \\
1977 & 1.700 & 321 & 2.021 \\
1978 & 1.688 & 354 & 2.042 \\
1979 & 1.744 & 338 & 2.083 \\
1980 & 1.811 & 422 & 2.233 \\
1981 & 1.781 & 446 & 2.227 \\
$1982^{*}$ & 1.786 & 561 & 2.347 \\
\hline
\end{tabular}

- Valores preliminares

Fonte: CMTC, ANTP - Estatísticas. Revista dos Transportes Públicos ANTP, São Paulo, (15) 118, mar. 1982. 
Esta mesma tendência pode ser verificada em outras grandes cidades como o Rio de Janeiro, Curitiba, Belém e Fortaleza (tabela 5).

Tabela 5 - Viagens anuais de ônibus nos municípios-sede das regiões metropolitanas

\begin{tabular}{l|r|r|c}
\hline & \multicolumn{3}{c}{ (milhões de viagens) } \\
\hline Rio de Janeiro & 1979 & 1981 & $1981 / 79$ \\
Curitiba & 1.436 & 1.317 & $-8,3 \%$ \\
Porto Alegre & 216 & 201 & $-6,9 \%$ \\
Belém & 303 & 362 & $+19,5 \%$ \\
Fortaleza & 187 & 181 & $-3,2 \%$ \\
Recife & 278 & 262 & $-6,1 \%$ \\
Salvador & 273 & 275 & $+0,1 \%$ \\
Belo Horizonte & 312 & 328 & $+5,1 \%$ \\
\hline Fonte: ANTP & 500 & 604 & $+20,8 \%$ \\
\hline
\end{tabular}

Fonte: ANTP

Nestas cidades observa-se, no período, um decréscimo que pode estar refletindo apenas uma redução na disponibilidade econômica dos usuários, dadas as condições de economia recessiva por que atravessamos e conseqüente redução de sua mobilidade. Essa hipótese é reforçada pelo fato de estar havendo, ao que tudo indica, um decrescimento concomitante nas viagens por automóvel. Em São Paulo por exemplo detectou-se no sistema viário principal, entre 1979 e 1981, uma redução de 5,4\% nesse volume. 9

Deve-se considerar no entanto que, se ainda não atingimos, estamos prestes a atingir aquele ponto de inflexão que nos levará, certamente, a uma redução da participação dos transportes coletivos nas viagens urbanas. Reverter essa tendência não parece tarefa fácil. A crise energética poderia ser um aliado. O programa de substituição da gasolina para o álcool, contudo, está beneficiando fundamentalmente o automóvel. Além de dispor de um combustível alternativo, os proprietários de carro se servem da gasolina a preços que, após o grande aumento de 1979, vem decrescendo em termos reais nos últimos anos. (figura 3 )

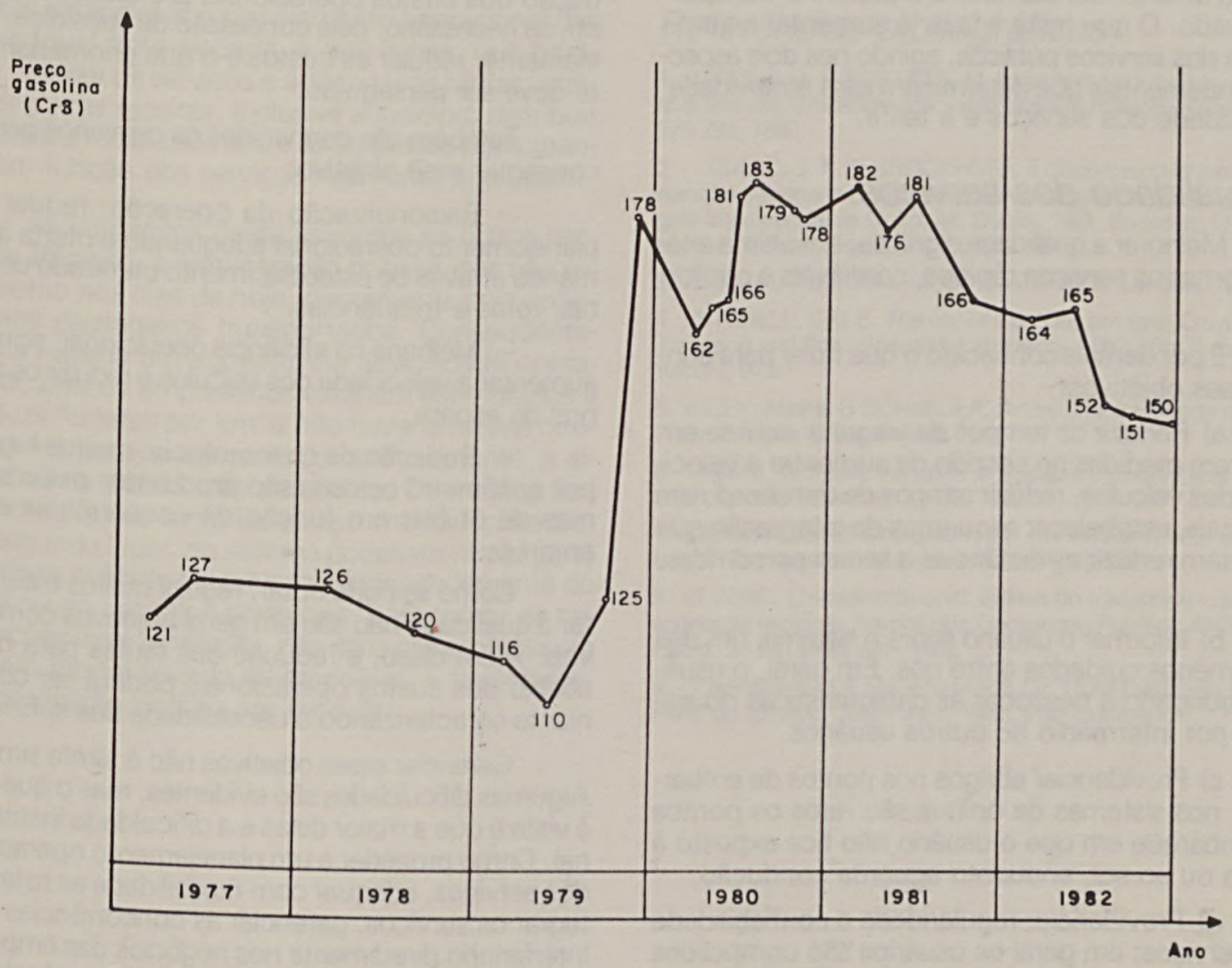

Fonte: CET

Deflatores - IGP - Conjuntura Econômica FGV

FIG. 3 - EVOLUCAAO DOS PREÇOS DA GASOLINA (valores em $\mathrm{Cr} \mathbf{s}$ de out./82) 
Da mesma forma, os subsídios operacionais (item 2) são sentidos como progressivamente necessários, na medida que se considerar o transporte público como um serviço de caráter social e que houver, portanto, um controle das tarifas no sentido de minimizar seu impacto no orçamento familiar dos usuários. Como conseqüência, a tendência seguinte poderá ser a da estatização dos serviços (item 3).

\section{O que fazer?}

É fundamental que os que decidem se conscientizem da necessidade de um esforço concentrado e coerente. Historicamente, o que se verifica é um esforço disperso e tardio. Até 1975, por exemplo, quando se criou a EBTU, não existia no governo federal órgão algum que tratasse especificamente dos transportes urbanos.

A operação dos sistemas de transporte coletivo, à exceção dos metrôs, tem sido, até pouco tempo - em muitos lugares é até hoje - relegada a segundo plano. Como foi visto, a competição com o automóvel será uma competição difícil. O mercado terá uma tendência natural a preferir o transporte privado. $\mathrm{O}$ que resta a fazer é aumentar a atratividade dos serviços públicos, agindo nos dois aspectos fundamentais que determinam essa atratividade: a qualidade dos serviços e a tarifa.

\section{A qualidade dos serviços}

Melhorar a qualidade significa, em última análise, tornar os serviços rápidos, confiáveis e confortáveis.

É por demais conhecido o que fazer para atingir esses objetivos:

a) Reduzir os tempos de viagens: aqui se enquadram medidas no sentido de aumentar a velocidade dos veículos, reduzir tempos de transbordo em terminais, estabelecer esquemas de integração que permitam reduzir as distâncias a serem percorridas, etc.

b) Informar o usuário sobre o sistema: um dos itens menos cuidados entre nós. Em geral, o usuário é obrigado a descobrir as características do sistema por intermédio de outros usuários.

c) Providenciar abrigos nos pontos de embarques: nos sistemas de ônibus são raros os pontos de embarque em que o usuário não fica exposto à chuva ou ao sol, enquanto aguarda condução.

d) Providenciar regularidade e confiabilidade nos serviços: em geral os usuários são compelidos a procurar o transporte em horários antecipados bem mais do que seria estritamente necessário, para assegurar-se que chegarão a tempo no destino. e) Providenciar conforto na viagem: para o empresário, quanto maior a lotação do veículo, maior será o seu lucro.

Apenas com relação ao primeiro item - reduzir os tempos de viagens - algo significativo tem sido feito nos sistemas de ônibus, principalmente acelerar as velocidades mediante o estabelecimento de esquemas prioritários no tráfego. São Paulo, por exemplo, já tem instalados cerca de $100 \mathrm{~km}$ de faixas exclusivas para ônibus e estas soluções proliferam também em outras capitais. Da mesma forma, foram concebidos e implantados em São Paulo esquemas especiais para reduzir os tempos de embarque nos pontos de parada mais congestionados - sistema COMONOR - e tais esquemas foram também aplicados com sucesso em Porto Alegre.

Os serviços prestados pelos metrôs são os que tiveram condições de melhor atender ao usuário em relação aos aspectos acima arrolados.

\section{Redução das tarifas}

Essa redução poderá ser conseguida pela redução dos custos operacionais preferencialmente, ou, se necessário, pela concessão de subsídios. Obviamente, reduzir os custos é o que prioritariamente deve ser perseguido.

Também são conhecidos os caminhos para se conseguir esse objetivo:

- Racionalização da operação: requer um planejamento operacional adequando a oferta à demanda através do estabelecimento otimizado de frotas, rotas e freqüências.

- Melhoria na eficiência operacional: significa aumentar a velocidade dos veículos e reduzir os tempos de espera.

- Redução de concorrência: muitos lugares por quilômetro ociosos são produzidos pelos sistemas de ônibus em função da concorrência entre empresas.

Como se pode notar, reduzir custos e aumentar a qualidade não são em geral objetivos compatíveis. Além disso, a redução das tarifas para niveis abaixo dos custos operacionais poderá ser conveniente caracterizando a necessidade dos subsídios.

Gerenciar esses objetivos não é tarefa simples. Algumas dificuldades são evidentes, mas o que salta à vista é que a maior delas é a dificuldade institucional. Como proceder a um planejamento operacional dos serviços, adequar com flexibilidade as rotas, integrar os serviços, gerenciar as concorrências etc., interferindo diretamente nos negócios das empresas envolvidas? Talvez tenha sido essa a grande dificuldade que inibiu sobremaneira um desenvolvimento mais adequado dos transportes coletivos. 
É importante que a solução possibilite o controle dos serviços pelo poder concedente, para que se possam atender os objetivos comunitários e que, ao mesmo tempo, não abra mão de eficiência das empresas privadas.

A solução que nos parece mais conveniente é dividir o fornecimento dos serviços de transporte coletivos urbanos em duas partes distintas:

- produção dos serviços;

- e comercialização dos serviços.

A produção dos serviços deveria ser descentralizada. As empresas seriam responsáveis em produzir uma certa quantidade de 'lugares por km', investindo na aquisição dos veículos, sua manutenção, operação etc. Essas empresas, para tanto, manteriam independentes sua identidade, sua capital e sua gerência empresarial.

Já a comercialização dos serviços deveria ser centralizada em órgão do poder público ou, preferencialmente, em órgão que associe as empresas privadas e públicas. Esse órgão teria as funções básicas de: estabelecer o planejamento operacional das linhas (qual frota alocada, a que linhas, que horários); vender os serviços e arrecadar as tarifas; arrecadar outras receitas, inclusive subsídios; distribuir os totais arrecadados entre as empresas participantes em função dos serviços realmente prestados.

As vantagens desse esquema se fazem senSíveis. Primeiro, a remuneração dos serviços não seria, como nos dias de hoje, diretamente porporcional aos passageiros transportados. Conseqüentemente haveria um aumento na flexibilidade operacional, pois os empresários estariam estimulados a produzir 'lugares por km' e não haveria razões consideráveis para se oporem, como atualmente, a alterações na distribuição das linhas. Da mesma forma, integrações tarifárias seriam muito facilitadas. Em segundo lugar, do sistema poderiam tomar parte empresas públicas ou privadas, independemente do porte ou do capital; é certo que, para tornar as negociações mais facilitadas, não seria conveniente um número muito elevado de empresas. E finalmente, a implantação poderia ser modular.
Uma primeira fase poderia ser, por xemplo, composta pelo agrupamento de empresas estatais. Assim, em São Paulo, o metrô, o CMTC, a RFFSA e a FEPASA poderiam constituir esse órgão central, as empresas privadas a ele se incorporando em uma segunda etapa. A idéia de esquemas institucionais semelhantes a esse já é antiga, o exemplo mais clássico sendo a implantação feita em Hamburgo, em 1965. A dificuldade aparente mais importante que tem inibido o desenvolvimento dessa idéia, ao longo do tempo, é a presença de interesses privados no esquema. No entanto, como anteriormente mencionado, poder-se-ia estabelecer um arranjo inicialmente entre os operadores estatais - nas regiões onde isso se justificasse, como São Paulo por exemplo - , havendo posterior incorporação dos operadores privados.

Além disso, faz-se mister mencionar que já foi quebrado há algum tempo o tabu de negociações envolvendo aspectos econômicos/financeiros com os empresários privados. Os esquemas de caixas de compensação implantados em Porto Alegre, Belo Horizonte e Curitiba são um bom exemplo disso.

\section{Referências bibliográficas}

1. BATES, J. J. \& ROBERTS, M. Indicators for future car ownership and use. Transport policy and decision making, Hague, 1 (1): 275-290, 1980.

2. ISAAC, J. K. \& BROCKHOFF, E Coopération et intégration dans les transports publics des grandes agglomerations. In: Congrès International de L'uitp, 44, Dublin, 1981. Bruxelles, Union Internationale des Transports Publics, 1981.

3. ANNUAL ABSTRACTS OF STATISTICS, London, 1981.

4. MITCHELL, C.G.B. The use of local bus services. Crowthorne, Transport and Road Research Laboratory, 1980, 30p. (Laboratory Report, 923).

5. BIGEY, Michel \& SCHMIDER, André. Les transports urbains. Paris, Editions Universitaires, 1971.

6. TABORI, G. Public transport in Budapest; present and future. UITP Revue, Bruxelles, 31 (3), 1982.

7. BAYLISS, David. One billion new city dwellers; how will they travel? Transportation, Amsterdam, 10 (4), 1981.

8. SEVERO, Cloraldino Soares. Efeitos do transporte urbano na economia nacional. Revista dos Transportes Públicos ANTP, São Paulo, 3 (10): 9-45, dez. 1980.

9. COMPANHIA DE ENGENHARIA DE TRÁFEGÒ (São Paulo). Perfil do trânsito. São Paulo, 1982. (não publicado). 
(1) 